\title{
Becoming a Grandparent and Early Retirement in Europe
}

\author{
Jan Van Bavel* \& Tom De Winter** \\ *Centre for Sociological Research, University of Leuven \\ ** Interface Demography, Vrije Universiteit Brussel
}

Key author and author for correspondence:

Jan Van Bavel

Centre for Sociological Research

Parkstraat 45 - bus 3601

BE-3000 Leuven

Belgium

e-mail: Jan.VanBavel@ soc.kuleuven.be

\section{Statement of funding}

This work was supported by the Seventh Framework Program of the European Commission in the context of the MULTILINKS research project [217523].

\section{Acknowledgements}

The authors are grateful to all participants in the MULTILINKS project for their feedback about an earlier version of this paper. Special thanks go to Pearl Dykstra, who coordinated that project. We also thank the members of the TransEurope group, a research network funded by the European Science Foundation, and particularly Hans-Peter Blossfeld and Melinda Mills for their stimulating comments about this study.

\begin{abstract}
Given that the funding of pensions is at issue, governments across Europe now try to discourage early retirement. Yet, international research about the determinants of early retirement based on appropriate micro-data is scarce. In addition, studies have tended to look at the retiring generation in an isolated way, ignoring the intergenerational ties that may play a role in their retirement decision. This paper uses the European Social Survey, covering 22 countries from all regions of Europe, to investigate to what extent becoming a grandparent affects early retirement in European countries. We apply multilevel event history modelling to data from the third round of the European Social Survey and from the Multilinks database on intergenerational policy indicators. We find that becoming a grandparent speeds up retirement, especially at the round ages of 55 and 60 years. However, the effect is statistically significant only for women, not for men. We discuss differences between countries, including the role played by differences in formal child care provisions.
\end{abstract}

KEYWORDS: grandparenthood, retirement, intergenerational relations, child care, Europe

- Version February 2013, Accepted for publication in European Sociological Review - 


\section{Becoming a Grandparent and Early Retirement in}

\section{Europe}

\section{Background}

Since more than a decade, the employment rate in the ageing populations of Europe has been high on the political agenda. During its meeting in Lisbon, May 2000, the European Council declared that the European Union (EU) should raise its overall employment rate to 70 per cent and the female employment rate to more than 60 per cent by 2010 . Major tools to reach this goal are the stimulation of female labour force participation and the raising of the average actual retirement ages (European Commission, 2010; Buchholz et al., 2011).

In this debate about ageing, employment and retirement, there is a tendency to take a somewhat one-sided look at retirement as a primarily negative status, i.e. as a status of no longer being active. This negative perspective may be related to the fact that it has long been assumed that life after leaving the workforce would be characterized by disability and decline. Indeed, disability and decline during old age were a justification for retirement in the first place. Yet, in the more recent social scientific literature about ageing, there has been a trend towards making a more optimistic assessment of the "Third Age" as a period of new opportunities. Leaving the workforce is no longer automatically equated with dependency in physical and financial terms (Higgs et al., 2003). Important preconditions for this more optimistic perspective to the Third Age have been increases in life expectancy and improvements in the health of the older population.

Apart from having more spare time to enjoy life, retired people often provide unpaid help and care to family and friends. Younger retired people often look after older generations who are suffering from illness, impediments, and disabilities. Or they provide care and help 
to younger generations, for example by stepping in for child care. A recent paper suggest that grandprantal involvement in childcare might even affect school performance of grandchildren (Modin, Erikson and Vågerö, 2013). Next to their social value, such unpaid services also represent an economic asset that is often neglected in the debate about early retirement. To a large extent, the help they provide is essential so that it would have to be substituted with paid services. In addition, in the case of childcare, the help provided often facilitates the labour force participation of mothers with young children. The rising labour force participation of women is an essential factor in the intended increase of the employment rate, aimed at by the European and national policies. So, if European countries succeed in postponing retirement, there are not only economic benefits but also costs. These costs have largely been neglected.

It is clear that the age at retirement will be an important factor in the challenge posed by ageing to social policy in Europe. This paper will contribute to the literature about the determinants of the timing of retirement. The retirement literature commonly distinguishes between push and pull effects. The former entail circumstances which hinder the continuation of employment of late-career workers and push them out of the labour market. The latter include circumstances that make retirement an attractive option and pull people out of the labour market. Company restructuring is an example of a pushing factor; attractive pension schemes are an example of a pulling factor (Buchholz et al., 2006). Most research has focused on push effects. Much less research has been done about more factors pulling people into retirement (Maule, Cliff and Taylor, 1996). Existing studies on pull effects have concentrated on the attraction of generous pension schemes (Dorn \& SousaPoza, 2010).

This paper addresses the role of a potential pulling factor that has largely been neglected in the existing literature: to our knowledge, this paper is the first that tries to empirically assess the effect of becoming a grandparent on the timing of retirement across Europe. We 
know that retired people often provide childcare to their grandchildren. Can we find evidence that entry into grandparenthood accelerates exit from the labour force into retirement? To answer that question, we use the third round of the European Social Survey, with fieldwork carried out late 2006, early 2007. Since the data allow us only to address full retirement, incidences where becoming a grandparent stimulates partial retirement are left out of the picture.

The next paragraph discusses findings from earlier work on the determinants of early versus late retirement. These determinants will not be analysed empirically in this paper but the review provides a background for our analysis of the effect of the transition to grandparenthood, which has not been studied so far. We then describe patterns of childcare provision by grandparents across Europe. Subsequently, we introduce our data and methods and discuss our empirical results.

\section{The timing of retirement}

People retire for different kinds of reasons. One set of reasons can be called institutional, the other set relates to individual level characteristics (Schils, 2008; Dorn \& Sousa-Poza, 2010; Buchholz et al., 2011).

\section{Institutional factors}

A basic institutional factor is the legal retirement age: in most European countries, retirement requires a standard retirement age, and in some cases also a minimum contribution period. The standard retirement age represents the age at which a person may or must retire in order to be entitled to receive a full pension benefit. In 2004, in the majority of European countries, the standard age for men was 65 (see Figure 1), with Norway being the only country with a higher standard age, namely 67 years. In the majority of countries, the standard age was below 65 for women, with Norway again being the exception with age 67 as the standard retirement age for women as well. Typically, the 
standard retirement age is between 60 and 65 years for women. Most countries appear to be moving towards a universal standard pensionable age of at least 65 years (European Commission, 2010).

In most countries many people retire before reaching the standard retirement age. This pattern is so distinctive that the actual mean retirement age lies below the standard age in all countries (see Figure 1). There clearly is a connection between the standard and the actual mean age, both for men and for women: the average actual age tends to be higher in countries with a higher standard age at retirement. Looking at the figures for 2004 displayed in Figure 1, 33 per cent of the between-country variance in average ages at retirement for men can be explained by the between-country variance in standard ages. For women, 31 per cent can be explained. Yet, other institutional factors also play a role.

Early retirement is made possible institutionally by a range of social security arrangements. Sometimes, institutional arrangements have even given incentives to retire earlier (Schils, 2005, 2008). In the past decades, many European countries have encouraged various forms of early exit from the labour force, partially or fully, with main tools being unemployment insurance, extended access to sickness or disability benefits, or the development of specific pre-retirement schemes (Blanchet, Brugiavini and Rainato, 2005). The availability of these pathways to early retirement differs strongly (Hofäcker et al., 2006; Buchholz et al., 2011). Schils $(2005,2008)$ differentiates between four clusters of early retirement systems, depending on the generosity of the benefits paid to early retirees and on the flexibility of the pathways out of the labour market. She found that the generosity and the flexibility strongly stimulate early retirement, at least in the investigated Western European countries. Countries with high flexibility and generosity, like Austria, Belgium, Germany, and the Netherlands, have high early retirement rates, i.e. they have low actual ages at retirement as compared to the standard age. Using data from the 2005 round of the Survey of Health, Ageing and Retirement in Europe (SHARE), Fischer and 
Sousa-Poza (2006) confirmed that generous early retirement options encourage early exit from the labour market. More specifically, they found that the level of pension wealth accrual, i.e. the opportunity cost of retiring early rather than late, exerts a strong influence on early retirement decision: if the amount of pension benefit foregone in case of early rather than late retirement is high, people are less inclined to take the early option.

\section{<Insert Figure 1 here>}

The generosity of early retirement schemes not only affects the age at exit from the labour market but also the selectivity in terms of individual characteristics. In countries with a generous system, early exit is less selective, for example because most people can afford, financially, to stop working for pay. In ungenerous systems, early retirement is not only less widespread in quantitative terms but also more selective in qualitative terms: only the better off who earned a high wage or salary during their careers can afford an early exit. Consequently, in such countries, early retirement will be more widespread among the highly educated (Schils, 2008).

\section{Individual level factors}

Even if country-specific pension systems strongly affect early retirement by making it more or less attractive, individuals in most cases still have the freedom to decide between continuing to work or exit from the labour market. Research on personal motivations behind retirement decisions has predominantly focused on factors pushing people out of the labour market. Often these factors have a negative connotation, like bad health (Van Solinge \& Henkens, 2010), impairments, or company restructuring. The financial affordability of early retirement clearly plays a role in the decision to stop working for pay or not (Hofäcker et al. 2006; Dorn \& Sousa-Poza, 2010). Early retirement motivated by the considerations that one can afford it represents one of the two models of early retirement 
that emerged in the literature during the 1980s (Higgs et al., 2003: 771), namely the one pertaining mainly to white collar professional and managerial workers. In the other model, more associated with blue collar occupations, the central motivation for early retirement is adjustment to a decline of physical health. Later on, during the 1990s, stress-related early retirement became increasingly common among white collar occupations (Higgs et al., 2003).

Research has found clear differences between men and women. This can be related to the fact that men and women usually have different working careers, typically with more interruptions and a higher prevalence of part-time work for women (Schils, 2005). The average age of retirement is lower for women than for men, but this may be entirely due to the fact that the legal retirement age is lower for women in many countries. After taking the legal age into account, Fischer and Souza-Poza (2006) found that female workers have a lower probability to retire before the standard age than men, which may be related to the fact that men tend to retire more often than women for health reasons. Further, characteristics of the spouse may also play a role (see e.g. Van Solinge \& Henkens, 2007), including his or her retirement.

In a British qualitative study about motives behind early or late retirement decisions, apart from the classic "negative" motives for early retirement (like bad health or dissatisfaction with the job held), there clearly emerged a more positive conglomerate of motivations, called the "Third Age exit" by the authors, where early retirement is a choice for a new stage in life with new, emerging opportunities. This perspective does not look at retirement anymore as a residual category but as a positive option, enabling a newly engaged lifestyle. The wish to spend more time with grandchildren is explicitly cited by some as a motivation for early retirement (Higgs et al., 2003).

\section{Grandparents and childcare}


Over the past few decades, female labour market participation has grown strongly, also for women with young children. As a result, childcare has become a major issue in the combination of paid work with family life. In this debate, a basic distinction is made between formal and informal childcare. Formal childcare is for pay and provided in crèches, nurseries, kindergarten and the like. Informal childcare is not for pay and provided by friends, neighbours and especially by the family. Grandparents typically play an important role in childcare provision to young parents, be it to varying degrees across the regions of Europe (Attias-Donfut, Ogg and Wolff, 2005; Saraceno, 2011; Jappens and Van Bavel 2012). Estimates based on the 2004 SHARE indicate that the percentage of grandmothers who provide child care almost weekly or more often ranges between around $20 \%$ in Sweden and Denmark to more than $40 \%$ in Italy and Greece. For grandfathers, the percentages are more limited, ranging from just below $15 \%$ in Sweden and Denmark to around $37 \%$ in Italy and Greece (Hand and Buber, 2009). SHARE data also indicate that people aged $50+$ devote on average 0,5 hours per day to child care for grandchildren (averaging over people with or without grandchildren). The amount of time spent on looking after grandchildren is higher for women than for men, and increases from northern to southern Europe (Croda \& Gonzalez-Chalepa, 2005).

In social contexts where the provision of formal childcare is limited, the preparedness of grandparents to step in may be an important factor in the fertility decisions made by working women, as well as in the decision about labour force participation of young mothers. In turn, the preparedness of grandparents to provide childcare on a regular basis is a function of their own labour force participation. In countries where grandparents, more particularly grandmothers, are mostly not in paid employment, the rates of regular grandchild care are higher. Also, if alternative childcare providers are less available in a country, grandchild care is more widespread (Attia-Donfut, Ogg and Wolff, 2005). In some countries, the role of grandparents in childcare is even stimulated by the government, for 
example by opening up parental leave entitlements to grandparents (as in the case of Bulgaria and Hungary, Saraceno, 2011: 80).

So, many grandparents seem to be prepared to take care of their grandchildren, especially if needed because of the lack of other forms of childcare. If routes of early retirement are present, childcare may therefore be a motivation for grandparents to retire earlier. Given that grandmothers more often provide childcare than grandfathers (Hank \& Buber, 2007), reflecting the gender pattern also common among parents, it may be expected that the effect of becoming a grandparent on retirement is stronger for women than for men. In addition, there is evidence that people who become a grandparent at an early age feel older than peers of the same age who don't have any grandchildren yet (Kaufman and Elder, 2003). Such feeling may provide an additional stimulus for early retirement.

Our research questions may be summarized as follows. First, does becoming a grandparent speed up retirement, i.e. does the rate of retirement before reaching the standard age increase upon becoming a grandparent? Second, is the effect of grandparenthood on early retirement, if there is any, stronger for women than for men? Third, is the effect of grandparenthood on retirement stronger in countries where cultural practices imply that the family is the provider of childcare and where formal childcare facilities are poorly developed?

\section{Data and methods}

We use micro-data from the third round of the European Social Survey (ESS3), with fieldwork carried out late 2006 to early 2007. Our motivation to use this database is threefold. First, this round asked respondents both about the year of retirement, if retired already, as well as about the year when their first grandchildren were born, if any. This retrospective information allows event history analysis taking the chronology into account, which is better suited for the identification of cause and effect. Second, the ESS3 does 
cover a wide range of European countries, from North to South as well as from East to West. This represents an added value for the literature since earlier research has tended to neglect post-communist countries in the Eastern part of Europe (although there are a number of country-specific studies, including Hamplová \& Pollnerová, 2006; Viera-Ramos \& Bukodi, 2011; Täht et al., 2011). Third, the data quality of the ESS3 is recognized to be high, as the international ESS team is very keen on monitoring standard procedures of sampling, minimizing non-response, and data cleaning (Stoop et al., 2010).

Since we are focusing on the effect of becoming a grandparent on retirement, we have selected from the ESS3 only respondents aged 50 years and older who have at least one own child. Also, people who were never active in the paid labour market for more than three months as well as women who declared to be housewives were removed from the sample. We dropped Ukraine and Switzerland from the sample because comparable data on standard pensioning ages were unavailable for these countries. Cyprus was removed from the ESS3 sample because comparable data on level of education were lacking for this country. In the end, 11.299 people aged 50 and above were used in the analysis. Table 1 gives information about the fieldwork period and sample sizes in the 22 countries selected for analysis. Table 2 reports basic descriptive statistics. In all countries, the total response rate was higher than $50 \%$ and in most cases more than $60 \%$; on average, the response rate was $63,6 \%$. Although it is not possible to calculate separate response rates for the selected sub-sample of people age 50 and over, studies indicate that response rates in this age range are somewhat higher than average in most countries, with Austria and Belgium being exceptions. In Spain, Ireland, and Great Britain, response rates among the older are considerably higher than among the younger part of the population (Stoop et al., 2010: 214217). 
<Insert Table 1 here>

<Insert Table 2 here>

We employ discrete time event history analysis to investigate the relation between grandparenthood and early retirement, following all people from age 50 onwards until their current age at the time of the survey. First, we will present the results of a purely descriptive life table approach. Next, we turn to multivariate regression analysis. More specifically, we fit multilevel hazard models, using a logistic specification of the rate of entry into retirement, with a random effect added on the country level. For the country level variables, we draw on the Multilinks database on intergenerational policy indicators (Keck, Hessel and Saraceno, 2009).

The basic set-up of our models looks like this:

$$
\ln \frac{h_{i c}(t, t+1)}{1-h_{i c}(t, t+1)}=\alpha_{t}+\beta_{0 c}+\beta_{1} G_{i c t}+\beta_{2} X_{i c}
$$

where $h_{i c}$ is the discrete time hazard rate of retirement at age $t, \alpha_{t}$ is the intercept at age $t$ (with $t=0$ corresponding to age 50). $\beta_{0 c}$ is the country effect on the rate of retirement, assumed to be a random variable drawn from a normal distribution and with mean and variance to be estimated from the data. $\beta_{1}$ is the main parameter of interest, i.e. the effect of being a grandparent on the rate of retirement, with $G_{i c t}$ a time-varying dummy variable indicating for person $i$ in country $c$ whether he or she has already become a grandparent at age $t$. Finally, $\beta_{2}$ represents the effect of the time-constant control variables.

\section{Findings from life table analysis}

Figure 2 plots life table discrete time hazard rates along with the implied survivor function for the pooled sample with all countries combined, with separate lines for those 
who have made the transition to grandparenthood and those who have not yet made the transition. These descriptive data suggest a tendency for people to retire earlier once they have at least one grandchild. The survivor function indicates that, at age 59, 31 per cent of the people who have not yet had any grandchildren were already retired, while this was 43 per cent for people with at least one grandchild. At age 64, 65 per cent of men and women without grandchildren were retired, while this was 73 per cent of the people with at least one grandchild. Inspection of the age-specific hazard function strongly suggests that the difference between grandparents and people without grandchildren is largely made in the peak years of early retirement, i.e. the "round" ages of 55 and 60 years. At other ages, the difference between the two groups is small at most.

\section{<Insert Figure 2 here>}

\section{<Insert Figure 3 here>}

Figure 3 gives the life table survival curves separately for men and women. This plot suggests that the effect of grandparenthood on early retirement was small for men but markedly larger for women, as expected given the greater role played by grandmothers in childcare. In the pooled sample, just over 50 per cent of the grandmothers who were previously active on the labour market are retired before reaching age 60, as compared to 37 per cent of the women without any grandchildren. Among men, the difference between grandfathers and men without any grandchildren is much smaller: before reaching age 60 , 27 per cent of the grandfathers have retired already, while this is 23 per cent of the men without grandchildren. These figures suggest that, for women, up to 13 percentage points of retirement before age 60 could be accounted for by the transition to grandparenthood, while this is only 4 percentage points for men.

Figure 4 plots the survival curves separately for each country. Given the fact that the number of observations in each cell of the plot is limited, the curves are more erratic. Still, the general pattern emerging is that, if anything, entry into retirement is somewhat earlier 
for those who already have at least one grandchild. This seems to be particularly the case in Austria, Estonia, Hungary, Latvia, Slovenia, and Slovakia. Again, in many cases there is a noticeable jump into retirement by grandparents at the round ages of 55 and 60 . In the Scandinavian countries (Norway, Sweden, Denmark), there is no visible effect of grandparenthood on exit from the labour market. Also in Western European countries like the Netherlands, Belgium and France, there is hardly any noticeable difference between the curves for grandparents and those without any grandchildren. However, these are just bivariate descriptive analysis that do not account for differences between countries in terms of the distribution by level of education, for example, or the standard age of retirement. We now turn to multilevel regression analysis to take such differences into account and estimate the net grandparenthood effect.

\section{<Insert Figure 4 here>}

\section{Regression analysis}

Table 3 gives the results from the multilevel discrete time hazard models of entry into retirement, with random intercepts on the country level. Model (1) is for all selected respondents aged 50 and above and includes a significantly positive age effect on retirement. There is a positive effect of becoming a grandparent on the speed of exit from the labour market before reaching the standard retirement age: once people have at least one grandchild, the likelihood that they retire early increases significantly. The odds of retirement are estimated to increase with 14 per cent upon becoming a grandparent (i.e. the odds ratio associated with the effect of grandparenthood can be calculated $\exp (0.128)=$ 1.14). This effect of grandparenthood applies as long as people have not yet reached the standard age of retirement applicable to their gender. If grandparents have not retired before reaching that age, their odds of subsequent retirement are significantly lower than for peer without grandchildren. Indeed, there is a statistically significant interaction effect 
between the status of grandparenthood and having reached the standard age: for elderly people without grandchildren, the effect of reaching the standard age on the retirement rate is positive, but this is not the case for grandparents. So, in sum, the overall picture is that, for grandparents, the highest retirement rates are observed before the standard age, while for people without grandchildren, the highest retirement ages are observed upon reaching the standard age.

Apart from that, there are equally statistically significant effects of having a "round" age on the retirement age: people are more likely to retire at ages 55, 60, and 65 . The length of the working career also matters: people who started to work in their first job at a later age, are less likely to retire early. The level of education has a statistically significant effect running in the same direction: the higher the level of education, the lower the rate of exit from the labour market. Men have significantly lower retirement rates than women, even after controlling for whether or not they have reached the standard retirement age applicable in their country and for their gender.

From the descriptive analysis, it appeared that the jumps towards earlier retirement were particularly made by grandparents at the round ages of 55 and 60 years. Therefore, models (2), (3), and (4) include the interaction between these round ages and grandparenthood, i.e. to check whether these ages of retirement are peaking stronger for grandparents than for the others. In addition, given the expected difference between men and women, confirmed by the descriptive analysis, the models were run separately for women and men.

The results of models (2) to (4) all indicate that the effect of grandparenthood on early retirement is limited to the peak ages of 55 and 60 years: after inclusion of their interaction with grandparenthood, the effect of grandparenthood for the other ages vanishes and is no longer statistically significant. Also, the grandparenthood effect is only statistically significant for women (model 2), not for men (model 3). 
A drawback of ESS3 is that is does not include retrospective information about health and wealth, while we know that these factors play an important role at the time when the decision is made to retire or not. This will not bias the estimated effect of becoming a grandparent to the extent that grandparenthood is not correlated with health and wealth (Wooldridge, 2003: 89-94). Still, as a further robustness check for the effect of grandparenthood, we estimated model (4), using data only from respondents who declared that their health generally was fair, good, or very good; and that they could cope, or even live comfortably, from their current income. Both subjective indicators refer to the situation at the time of the interview rather than at the time of the retirement decision. Therefore, it is not a good idea to include them as covariates in the models: the income situation will at least partly be determined by the retirement decision, and since health declines with age, even if the current health situation is bad, this will often not have been the case at a younger age, when early retirement was considered. Therefore, we reasoned the other way around: since income goes down upon retirement and since health problems become more frequent with age, then if we select only the ones who still feel healthy and wealthy, then their health and wealth situation at a younger than the current age will also have been relatively good in most cases.

Put another way, in model (4), we have tried to keep health and wealth constant at a positive value and then re-estimated the model. The results confirm our earlier conclusion about the positive effect of grandparenthood, but only at the round age of 55 years. At this age, the effect of becoming a grandparent on the rate of exit from the labour force is estimated to be stronger than in the earlier models, even stronger than in model (2) estimated for women only. Grandparents who currently feel to be in good health and who declare to have no serious financial worries are estimated to be 124 per cent more likely to retire at age 55 compared to age peers without any grandchildren. 
The models discussed so far estimate one overall effect of grandparenthood, i.e. for all countries combined. Yet, we expect that the effect of grandparenthood on the timing of retirement will vary by country. Therefore, model (5) in Table 4 includes random slopes for grandparenthood: the model explicitly includes a parameter accounting for country-level variety in the effect of having grandchildren.

The inclusion of country level variability in the effect of grandparenthood still leaves a strong overall average effect of grandparenthood on early retirement, but it is again limited to the "round" retirement ages of 55 and 60 years. On average across countries, we estimate the likelihood of entry into retirement for a 55 year old grandparent to be 88 per cent stronger than for a 55 year old without any grandchildren. The other fixed effects in model (5) are consistent with our earlier estimates.

Figure 5 plots the best linear unbiased predictors (BLUPs) for the country effect (Snijders \& Bosker, 1999). Consistent with evidence from other sources (e.g. European Commission, 2010), retirement tends to be earlier than average in most post-communist countries. Retirement is late in Denmark, the Netherland, Spain, and especially in Portugal, Sweden, Norway, Great Britain and Ireland. The large prediction intervals around the BLUPs for the country-specific deviation from the average slope for grandparenthood indicate large uncertainty about how things are exactly in each country. In some countries, most notably in Poland, Slovenia, and Romania, the effect of grandparenthood is clearly smaller than average. In most other countries, including Sweden and Norway but not Denmark, the point estimate for the country difference is positive, indicating that the grandparenthood effect is most likely at least as strong as indexed by the overall fixed effect estimate. Uncertainty about the exact values is too large, however, to allow much country-specific interpretation.

\section{<Insert Figure 5 here $>$}


Finally, model (6) includes childcare coverage rates as a country level variable. The coverage rate included is the average of the rate for 0 to 2 and the rate for 3 to 5 year olds, as reported in the Multilinks policy database (Keck, Hessel and Saraceno, 2009). They are on a per cent scale and refer to the situation around the year 2004 but are used here as a proxy for the situation around the time when retirement decisions were made - so we work on the assumption that countries with relatively high rates in 2004 tended to have relatively high rates in other years as well.

The results indicate that people aged 50 and more tend to retire later in countries with higher childcare coverage rates: a ten per cent increase in formal childcare coverage is associated with a decrease in the retirement rate of about 23 per cent. Yet, the parameter for the interaction with the status indicator for grandparenthood is very small and not significant, indicating that the effect of childcare coverage is not typical for those who have already become a grandparent.

\section{Conclusion}

In the past years, the timing of retirement has become a very important policy topic in the context of ageing Europe. Yet, international research about the determinants of early retirement based on appropriate micro-data is scarce. In addition, it has tended to look at the retiring population in a one-sided way, ignoring the intergenerational ties that may play a role in the retirement decision. This paper has used a high quality international database with relevant micro-data, covering 22 countries from all regions of Europe, to try to start correcting such a view. Indeed, we have argued that having grandchildren may be one motivation for older people to retire earlier than at the standard age. It is a well-known fact that many grandparents, to varying degrees in different parts of Europe, provide unpaid services to young fathers and mothers. This fact is largely neglected in the debate about 
retirement and pensions. Still, the services provided by early retirees in good health represent a very important condition for the labour market participation of many parents, more specifically of many young mothers. Especially in countries and regions where public involvement in childcare provision is very limited, and where childcare is considered to be the duty of the family (see Saraceno, 2011), the role of grandparents may be crucial. Labour market participation by grandparents may hinder their involvement in childcare, and this may, conversely, stimulate people who have become a grandparent to retire earlier than otherwise would have been the case.

Of course, we are not arguing that grandparenthood is the only determinant of early retirement. On the contrary, our literature review discussed both institutional factors such as social security arrangements and individual-level factors such as health and financial affordability. These determinants were not studied empirically in this paper, but their importance has been verified in earlier studies. This is the first study that addresses the role played by the transition to grandparenthood in retirement on a European-wide scale.

We used the third round of the European Social Survey to estimate the effect of becoming a grandparent on the timing of retirement. Our results generally reveal that grandparenthood tends to stimulate earlier retirement. Typically, grandparents, if they retire early, exit the labour market at the round ages of 55 and 60 years. The effects are stronger for women than for men, i.e. stronger for the ones most often providing child care: for women, up to 13 percentage points of retirement before age 60 could be accounted for by the transition to grandparenthood, while this is at most 4 percentage points for men. We find statistically significant effects of grandparenthood on early retirement, also when we limit the analysis to people with at least fair health and wealth conditions.

The fact that the differences in early retirement between grandparents and those without grandchildren are largest at round ages 55 and 60 highlights that the personal motivations to retire are only part of the story. Institutional regulations may facilitate actual retirement 
at specific ages, and these regulations seem to concentrate a lot on round ages. Future research will have to dig more into the details of the institutional regulations to illuminate the international differences found in this paper.

In line with previous research, retirement tends to be clearly earlier in the postcommunist countries of Eastern Europe and later in the Scandinavian countries as well as Great Britain and Ireland. The country differences in the effect of grandparenthood on the timing of retirement, however, are much less clear. The availability of formal childcare provision does play a role: in countries with higher childcare coverage rates, retirement tends to be later. However, this effect is not specific to people who have already become a grandparent. Therefore, it remains uncertain whether it picks up the pathway that we had in mind here, namely the trade-off between retiring early by grandparents in regions were public childcare provision is low on the one hand, and the later retiring by grandparents in regions with abundant public childcare. Yet, we think our results are clear enough to stimulate further research about the connection between becoming a grandparent and the retirement decision in Europe.

For policy makers, our results suggest that raising the actual age of exit out of the labour market, particularly among female employees, will generate an increased demand for child care substitutes, but not to the same extent in all European countries. In order to understand the international differences, future studies will have to look at economic (e.g. female labour market participation) and cultural factors (e.g. intergenerational obligations) that were not included in this study.

The data do not allow us to address partial retirement. As a result, we may be underestimating the true negative effect of becoming a grandparent on the amount of activity in the labour market. Indeed, for many grandparents, partial retirement may create the possibility to provide a few hours or days of child care per week, without withdrawing from the labour market entirely. Such instances are left out of the picture in this paper. 
Another limitation of the ESS is that it is a cross-sectional survey with no retrospective information about health and wealth. As a result, the effects of health factors and of the financial affordability cannot be estimated, even if these are well-known determinants of exit from the paid labour market. Maybe this can to some extent explain that we do not replicate the effects of gender and of level of education reported by Fischer \& Sousa-Poza (2006) based on the SHARE data. Another explanation for the difference is that the ESS, in contrast to SHARE, does include the post-communist countries from Eastern Europe. Future work should also look at socio-economic differentials more closely than we were able in this paper. The only control for socio-economic status included in this paper is the level of educational attainment. To the extent that socio-economic status is negatively related to the number of children and positively to the age at retirement, net of education, this correlation could confound the direct effect of grandparenting on retirement.

Finally, the data used in this article were collected in 2006 and 2007, just before a major financial and economic crisis broke out. This crisis will have an impact both on the macro level of institutional arrangements for pensions and on the micro level of the income of those considering early retirement. It remains to be seen how this affects the relationship between grandparenthood and retirement. On the institutional level, it can be expected that the trend towards higher legal retirement ages will be reinforced. A number of countries, like Denmark, the United Kingdom (UK), and Germany, have already taken measures to further increase the standard age in the future and to encourage more people to work longer (European Commission, 2010; Buchholz et al., 2011). In most European countries, people may continue working in the labour market even after reaching the standard retirement age, but not always unlimited and sometimes with exceptions. For example, in Ireland, deferred retirement is allowed until age 66; in Belgium, civil servants are not allowed to defer retirement (Keck et al., 2009). 
On the micro level, a grandparent with a steady job who would have quit his or her job in economically good times may think twice if unemployment is high in the younger generation. More generally, we expect that the relation between grandparenthood and retirement will depend on labour market prospects and earning potential in the younger generation.

\section{References}

Attias-Donfut, C., Ogg, J. and Wolff, F.-C. (2005). European patterns of intergenerational financial and time transfers. European Journal of Ageing, 2, 3, 161-173.

Blanchet, D., Brugiavini, A., and Rainato, R. (2005). Pathways to retirement, in BörschSupan, A., Brugiavini, A., Jürges, H., Mackenbach, J., Siegrist, J., and Weber, G. (eds.), Health, Ageing and Retirement in Europe. First Results From the Survey on Health, Ageing and Retirement in Europe. MEA, Mannheim, 246-252.

Buchholz, S., Hofäcker, D., and Blossfeld, H.-P. (2006). Globalization, accelerating economic change and late careers. A theoretical framework, in Blossfeld, H.-P., Buchholz, S., and Hofäcker, D. (eds.), Globalization, Uncertainty and Late Careers in Society. London: Routledge, pp. 1-23.

Buchholz, S., Rinklake, A., Schilling, J., Kurz, K., Schmelzer, P., and Blossfeld, H.-P. (2011). Aging populations, globalization and the labor market: comparing late working life and retirement in modern societies, in Blossfeld, H.-P., Buchholz, S., and Kurz, K. (eds.), Aging Populations, Globalization and the Labor Market. Cheltenham: Edward Elgar, pp. 3-32.

Croda, E. \& Gonzalez-Chapela, J. (2005). How do European Older Adults Use Their Time? In: Börsch-Supan, A. (ed.), Health, Ageing and Retirement in Europe. First 
results from the Survey of Health, Ageing and Retirement in Europe (pp. 265-271).

Mannheim: Mannheim Research Institute for the Economics of Aging.

Dorn, D. and Sousa-Poza, A. (2010). 'Voluntary' and 'involuntary' early retirement: an international analysis, Applied Economics 42, 4, 427-438.

European Commission. (2010). Green Paper. Towards Adequate, Sustainable and Safe European Pension Systems. European Commission, Brussels.

Fischer, J.A.V. and Sousa-Poza, A. (2006). The Institutional Determinants of Early Retirement in Europe. Department of Economics, University of St. Gallen, St.Gallen.

Hamplová, D. and Pollnerová, Š. (2006). Employment exits of older workers in the Czech Republic, in Blossfeld, H.-P., Buchholz, S., and Hofäcker, D. (eds.), Globalization, Uncertainty and Late Careers in Society. London: Routledge, pp. 281-300.

Hank, K. and Buber, I. (2009). Grandparents caring for their grandchildren: findings from the 2004 Survey on Health, Ageing and Retirement in Europe. Journal of Family Issues, 30, 1, 53-73.

Higgs, P., Mein, G., Ferrie, J., Hyde, M. and Nazroo, J. (2003). Pathways to early retirement: structure and agency in decision-making among British civil servants. Ageing \& Society, 23, 6, 761-778.

Hofäcker, D., Buchholz, S., and Blossfeld, H.P. (2006). Late careers in a globalizing world. A comparison of changes in twelve modern societies, in Blossfeld, H.P., Buchholz, S., and Hofäcker, D. (eds.), Globalization, Uncertainty and Late Careers in Society. London: Routledge, pp. 353-371.

Jappens, M. and Van Bavel, J. (2012). Regional family cultures and childcare by grandparents in Europe. Demographic Research, 27, 4, 85-120.

Kaufman, G. and Elder, G. H. (2003). Grandparenting and age identity. Journal of Aging Studies, 17, 3, 269-282. 
Keck, W., Hessel, Ph. and Saraceno, C. (2009). Database on Intergenerational Policy Indicators. Methodological Report. Wissenschaftszetrum Berlin für Sozialforschung/Multilinks project, Berlin.

Maule, A. J., Cliff, D. R. and Taylor, R. (1996). Early retirment decisions and how they affect later quality of life. Ageing \& Society, 16, 2, 177-204.

Modin, B., R. Erikson \& D. Vågerö. (2013). Intergenerational continuity in school performance: Do grandparents matter? European Sociological Review, doi: 10.1093/esr/jcs064

Saraceno, C. (2011). Childcare needs and childcare policies: a multidimensional issue. Current Sociology, 59, 1, 78-96.

Schils, T. (2005). Early Retirement Patterns in Europe. A Comparative Panel Study. Dutch University Press, Amsterdam.

Schils, T. (2008). Early retirement in Germany, the Netherlands, and the United Kingdom: a longitudinal analysis of individual factors and institutional regimes. European Sociological Review, 24, 3, 315-329.

Stoop, I., Billiet, J., Koch, A., and Fitzgerald, R. (2010). Improving survey response. Lessons learned from the European Social Survey. Wiley, Chichester.

Täht, K., Saar, E., and Unt, M. (2011). Increasing social inequality in later life since the 1980s in Estonia, in Blossfeld, H.-P., Buchholz, S., and Kurz, K. (eds.), Aging Populations, Globalization and the Labor Market. Cheltenham: Edward Elgar, pp. 231258.

Van Solinge, H. and Henkens, K. (2007). Involuntary retirement: the role of restrictive circumstances, timing, and social embeddedness. Journal of Gerontology: Social Sciences, 62B, 5, S295-S303. 
Van Solinge, H. and Henkens, K. (2010) . Living longer, working longer? The impact of subjective life expectancy on retirement intentions and behaviour. European Journal of Public Health, 20, 1, 47-51.

Viera-Ramos, A. and Bukodi, E. (2011). Late careers in Hungary: coping with the transformation from a socialist to a market economy, in Blossfeld, H.P., Buchholz, S., and Kurz, K. (eds.), Aging Populations, Globalization and the Labor Market. Cheltenham, UK: Edward Elgar, pp. 207-230.

Wooldridge, J. M. 2003. Introductory Econometrics. A Modern Approach. Mason (Ohio): Thomson. 


\section{Becoming a grandparent and early retirement in Europe}

Table $1 \quad$ Countries and country codes, fieldwork period, response rates and sample sizes

\begin{tabular}{|c|c|c|c|c|c|}
\hline Country & Code & Fieldwork period & Response rate $(\%)$ & Full sample size & Selected sample size \\
\hline Austria & AT & 18.07.07-05.11.07 & 64.0 & 2405 & 519 \\
\hline Belgium & $\mathrm{BE}$ & $23.10 .06-19.02 .07$ & 61.0 & 1798 & 404 \\
\hline Bulgaria & BG & 20.11.06-10.01.07 & 64.8 & 1400 & 496 \\
\hline Denmark & DK & 19.09.06-02.05.07 & 50.8 & 1505 & 563 \\
\hline Estonia & $\mathrm{EE}$ & $25.10 .06-21.05 .07$ & 65.0 & 1517 & 418 \\
\hline Finland & FI & 18.09.06-20.12.06 & 64.4 & 1896 & 708 \\
\hline France & FR & 19.09.06-07.04.07 & 46.0 & 1986 & 621 \\
\hline Germany & $\mathrm{DE}$ & 01.09.06-15.01.07 & 54.5 & 2916 & 881 \\
\hline Hungary & $\mathrm{HU}$ & 21.11.06-28.01.07 & 66.1 & 1518 & 514 \\
\hline Ireland & IR & $14.09 .06-31.08 .07$ & 56.8 & 1800 & 216 \\
\hline Latvia & LV & 28.06.07-02.09.07 & 71.2 & 1960 & 430 \\
\hline Netherlands & NL & $16.09 .06-18.03 .07$ & 59.8 & 1889 & 461 \\
\hline Norway & NO & $21.08 .06-19.12 .06$ & 65.5 & 1750 & 498 \\
\hline Poland & PL & 02.10.06-13.12.06 & 70.2 & 1721 & 400 \\
\hline Portugal & $\mathrm{PT}$ & $12.10 .06-28.02 .07$ & 72.8 & 2222 & 568 \\
\hline Romania & RO & 01.12.06-31.01.07 & 71.8 & 2139 & 569 \\
\hline Slovakia & SK & 01.12.06-28.02.07 & 73.2 & 1766 & 335 \\
\hline Slovenia & SI & $18.10 .06-04.12 .06$ & 65.1 & 1476 & 337 \\
\hline Spain & ES & $25.10 .06-04.03 .07$ & 65.9 & 1876 & 334 \\
\hline Sweden & ES & $21.09 .06-03.02 .07$ & 65.9 & 1927 & 682 \\
\hline Russia & RU & 18.09.06-09.01.07 & 69.5 & 2437 & 659 \\
\hline Great Britain & GB & 05.09.06-14.01.07 & 54.6 & 2394 & 686 \\
\hline
\end{tabular}

Table 2 Descriptive statistics for the sample used

\begin{tabular}{lcccc}
\hline Periods & Mean & S.D. & $N$ & $\%$ \\
\hline Current age & 64.8 & 20.1 & 11299 & \\
Age at first job & 18.8 & 6.1 & 11299 & \\
Gender & & & & \\
- male & & & 5635 & 49.9 \\
- female & & 5664 & 50.1 \\
Level of education & & & \\
- low & & 5014 & 44.4 \\
- medium & & 3983 & 35.2 \\
- high & & 2302 & 20.4 \\
Total & & 11299 & 100.0 \\
\hline
\end{tabular}

Source: own calculations based on ESS3. 
Table $3 \quad$ Multilevel discrete time logistic hazard models of entry into retirement: (1) all people aged 50 and more, (2) women versus (3) men, and (4) those who state to have at least a fair health and not finding it difficult to cope on present income

\begin{tabular}{|c|c|c|c|c|c|c|c|c|c|c|c|c|c|c|c|c|}
\hline & & ) All & & & (2) & 2) Wor & men & & (3) & ) Men & & & (4) & $\begin{array}{l}\text { Fair } \\
\text { inco }\end{array}$ & $\begin{array}{l}\text { health } \\
\text { me }\end{array}$ & \\
\hline & $\mathrm{b}$ & s.e. & $\mathrm{p}$ & & $\mathrm{b}$ & s.e. & $\mathrm{p}$ & & $\mathrm{b}$ & s.e. & $\mathrm{p}$ & & $\mathrm{b}$ & s.e. & $\mathrm{p}$ & \\
\hline intercept & -3.374 & 0.154 & 0.000 & $* * *$ & -3.445 & 0.197 & 0.000 & $* * *$ & -3.855 & 0.150 & 0.000 & $* * *$ & -3.478 & 0.156 & 0.000 & $* * *$ \\
\hline Age - 50 & 0.166 & 0.004 & 0.000 & $* * *$ & 0.159 & 0.006 & 0.000 & $* * *$ & 0.191 & 0.006 & 0.000 & $* * *$ & 0.169 & 0.005 & 0.000 & $* * *$ \\
\hline Grandparent? $($ ref $=$ no $)$ & 0.128 & 0.046 & 0.005 & $* *$ & 0.007 & 0.071 & 0.922 & & -0.004 & 0.087 & 0.963 & & 0.075 & 0.078 & 0.339 & \\
\hline Age $=55$ & 1.075 & 0.041 & 0.000 & $* * *$ & 1.379 & 0.057 & 0.000 & $* * *$ & 0.274 & 0.087 & 0.002 & $* *$ & 0.565 & 0.069 & 0.000 & $* * *$ \\
\hline$\ldots \mathrm{x}$ Grandparent & & & & & 0.510 & 0.127 & 0.000 & $* * *$ & 0.396 & 0.248 & 0.110 & & 0.804 & 0.173 & 0.000 & $* * *$ \\
\hline Age $=60$ & 1.527 & 0.041 & 0.000 & $* * *$ & 1.539 & 0.071 & 0.000 & $* * *$ & 1.435 & 0.058 & 0.000 & $* * *$ & 1.500 & 0.053 & 0.000 & $* * *$ \\
\hline$\ldots x$ Grandparent & & & & & 0.298 & 0.153 & 0.052 & $\circ$ & 0.296 & 0.165 & 0.073 & $\circ$ & 0.042 & 0.155 & 0.788 & \\
\hline Age $=65$ & 1.838 & 0.069 & 0.000 & $* * *$ & 1.875 & 0.102 & 0.000 & $* * *$ & 1.888 & 0.095 & 0.000 & $* * *$ & 1.890 & 0.082 & 0.000 & $* * *$ \\
\hline Age when starting first job & -0.026 & 0.002 & 0.000 & $* * *$ & -0.024 & 0.003 & 0.000 & $* * *$ & -0.024 & 0.004 & 0.000 & $* * *$ & -0.027 & 0.003 & 0.000 & $* * *$ \\
\hline Standard retirement age reached & 0.463 & 0.055 & 0.000 & $* * *$ & 0.479 & 0.077 & 0.000 & $* * *$ & 0.180 & 0.087 & 0.038 & $*$ & 0.372 & 0.071 & 0.000 & $* * *$ \\
\hline$\ldots x$ Grandparent & -0.519 & 0.086 & 0.000 & $* * *$ & -0.513 & 0.111 & 0.000 & $* * *$ & -0.272 & 0.149 & 0.069 & $\circ$ & -0.344 & 0.126 & 0.006 & $* *$ \\
\hline \multicolumn{17}{|l|}{ Level of education (ref=low) } \\
\hline - medium & -0.193 & 0.034 & 0.000 & $* * *$ & -0.194 & 0.047 & 0.000 & $* * *$ & -0.218 & 0.050 & 0.000 & $* * *$ & -0.186 & 0.046 & 0.000 & $* * *$ \\
\hline - high & -0.368 & 0.043 & 0.000 & $* * *$ & -0.434 & 0.063 & 0.000 & $* * *$ & -0.390 & 0.061 & 0.000 & $* * *$ & -0.294 & 0.052 & 0.000 & $* * *$ \\
\hline Gender $=$ male $($ ref $=$ female $)$ & -0.371 & 0.029 & 0.000 & $* * *$ & & & & & & & & & -0.225 & 0.038 & 0.000 & $* * *$ \\
\hline Variance of country effect & 0.450 & & & & 0.740 & & & & 0.315 & & & & 0.407 & & & \\
\hline $\mathrm{N}$ person years & 98806 & & & & 46365 & & & & 52441 & & & & 67242 & & & \\
\hline $\mathrm{N}$ countries & 22 & & & & 22 & & & & 22 & & & & 22 & & & \\
\hline
\end{tabular}

Source: own calculations based on ESS3 
Table $4 \quad$ Multilevel discrete time logistic hazard models of entry into retirement, people aged 50 and more, with (5) random slopes for grandparenthood on the country level plus (6) fixed effect of formal childcare coverage *

\begin{tabular}{|c|c|c|c|c|c|c|c|c|}
\hline & \multicolumn{3}{|c|}{ Model (5) } & \multicolumn{4}{|c|}{ Model (6) } & \\
\hline & $\mathrm{b}$ & s.e. & $\mathrm{p}$ & & $\mathrm{b}$ & s.e. & $\mathrm{p}$ & \\
\hline Intercept & -3.367 & 0.157 & 0.000 & $* * *$ & -2.045 & 0.604 & 0.001 & $* * *$ \\
\hline Age -50 & 0.168 & 0.004 & 0.000 & $* * *$ & 0.169 & 0.004 & 0.000 & $* * *$ \\
\hline Grandparent? $(\mathrm{ref}=\mathrm{no})$ & -0.016 & 0.081 & 0.843 & & -0.139 & 0.311 & 0.654 & \\
\hline Age $=55$ & 0.976 & 0.046 & 0.000 & $* * *$ & 1.020 & 0.047 & 0.000 & $* * *$ \\
\hline$\ldots x$ Grandparent & 0.634 & 0.109 & 0.000 & $* * *$ & 0.621 & 0.111 & 0.000 & $* * *$ \\
\hline Age $=60$ & 1.488 & 0.045 & 0.000 & $* * *$ & 1.521 & 0.046 & 0.000 & $* * *$ \\
\hline$\ldots \times$ Grandparent & 0.254 & 0.111 & 0.022 & $*$ & 0.224 & 0.113 & 0.048 & $*$ \\
\hline Age $=65$ & 1.838 & 0.069 & 0.000 & $* * *$ & 1.815 & 0.070 & 0.000 & $* * *$ \\
\hline Age when starting first job & -0.026 & 0.002 & 0.000 & $* * *$ & -0.026 & 0.003 & 0.000 & $* * *$ \\
\hline $\begin{array}{l}\text { Standard retirement age } \\
\text { reached }\end{array}$ & 0.441 & 0.056 & 0.000 & $* * *$ & 0.523 & 0.058 & 0.000 & $* * *$ \\
\hline$\ldots x$ Grandparent & -0.399 & 0.093 & 0.000 & $* * *$ & -0.425 & 0.095 & 0.000 & $* * *$ \\
\hline Medium education & -0.190 & 0.034 & 0.000 & $* * *$ & -0.205 & 0.036 & 0.000 & $* * *$ \\
\hline High education & -0.363 & 0.043 & 0.000 & $* * *$ & -0.352 & 0.045 & 0.000 & $* * *$ \\
\hline $\begin{array}{l}\text { Gender }=\text { male } \\
(\text { ref }=\text { female })\end{array}$ & -0.374 & 0.029 & 0.000 & $* * *$ & -0.369 & 0.030 & 0.000 & $* * *$ \\
\hline $\begin{array}{l}\text { COUNTRY } \\
\text { CHARACTERISTICS }\end{array}$ & & & & & & & & \\
\hline $\begin{array}{l}\text { Childcare coverage rate } 0 \text { - } \\
5\end{array}$ & & & & & -0.026 & 0.011 & 0.017 & * \\
\hline ... x Grandparent & & & & & 0.003 & 0.006 & 0.614 & \\
\hline Variance of country effect & & & & & & & & \\
\hline - intercept & 0.470 & & & & 0.3692 & & & \\
\hline - slope for Grandparent & 0.262 & & & & 0.2476 & & & \\
\hline $\mathrm{N}$ person years & 98806 & & & & 94648 & & & \\
\hline $\mathrm{N}$ countries & 22 & & & & 21 & & & \\
\hline
\end{tabular}

Source: own calculations based on ESS3

Note:

* Childcare coverage is the mean of the coverage rates for 0 to 2 year olds and the rates for the 3 to 5 year olds around the year 2004; both rates taken from the Multilinks database (Keck, Hessel, and Saraceno 2009) 
Figures

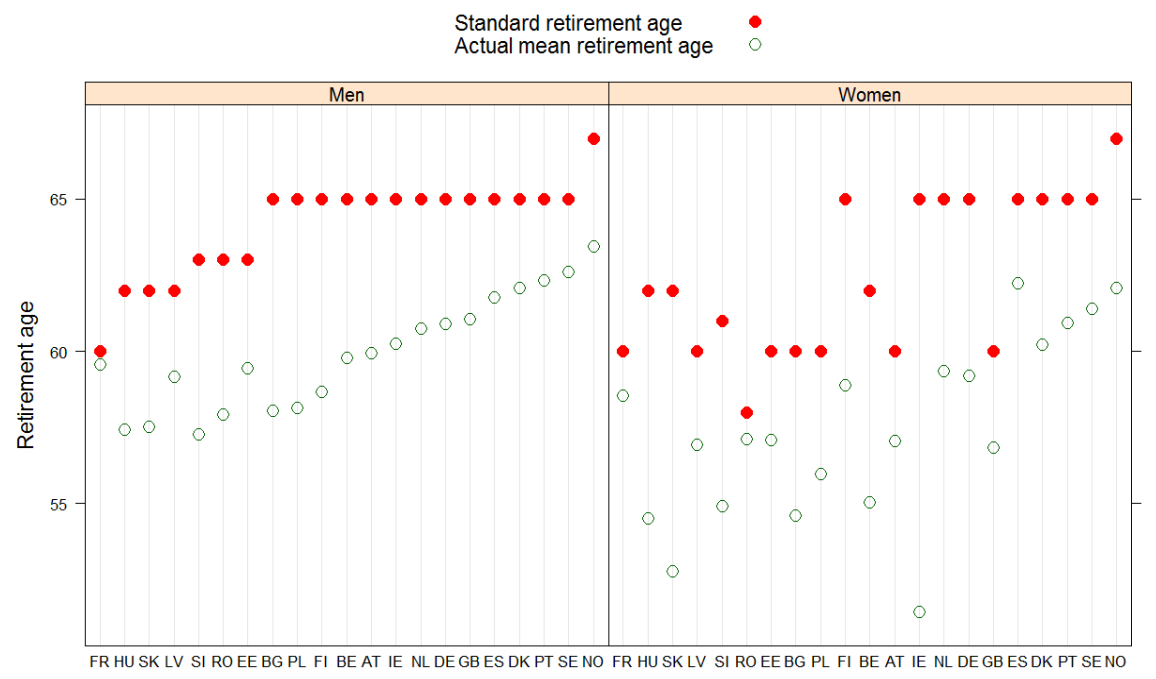

Figure 1. Standard retirement age (situation in 2004) and actual mean retirement age for men and women in European countries*

Source: multilinks database on intergenerational policy indicators (Keck, Hessel \& Saraceno 2009) for the standard retirement age; own calculations based on the $3^{\text {rd }}$ round of the European Social Survey for the actual mean age at retirement, calculated for respondents who are at least 65 years old.

* Country codes: AT Austria, BE Belgium, BG Bulgaria, DE Germany, DK Denmark, EE Estonia, ES Spain, FI Finland, FR France, GB Great Britain, HU Hungary, IE Ireland, LV Latvia, NL the Netherlands, NO Norway, PL Poland, PT Portugal, RO Romania, SE Sweden, SI Slovenia, SK Slovakia, 

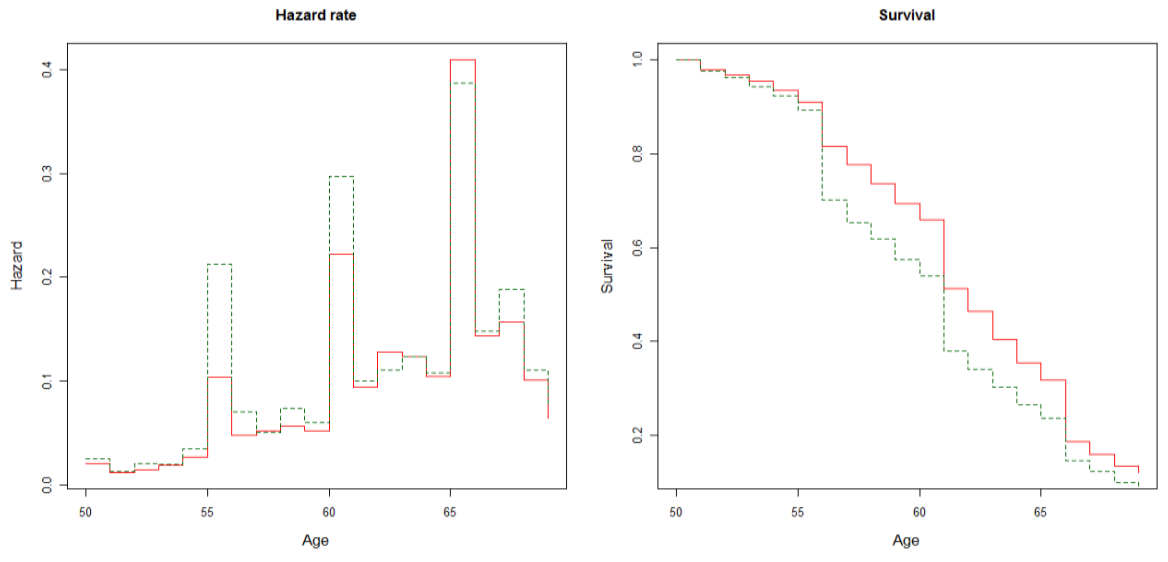

Has grandchild?

No

Figure 2. Life table hazard rate and survivor function for entry into retirement, all 22 countries pooled, by grandparenthood status

Source: own calculations based on ESS3 


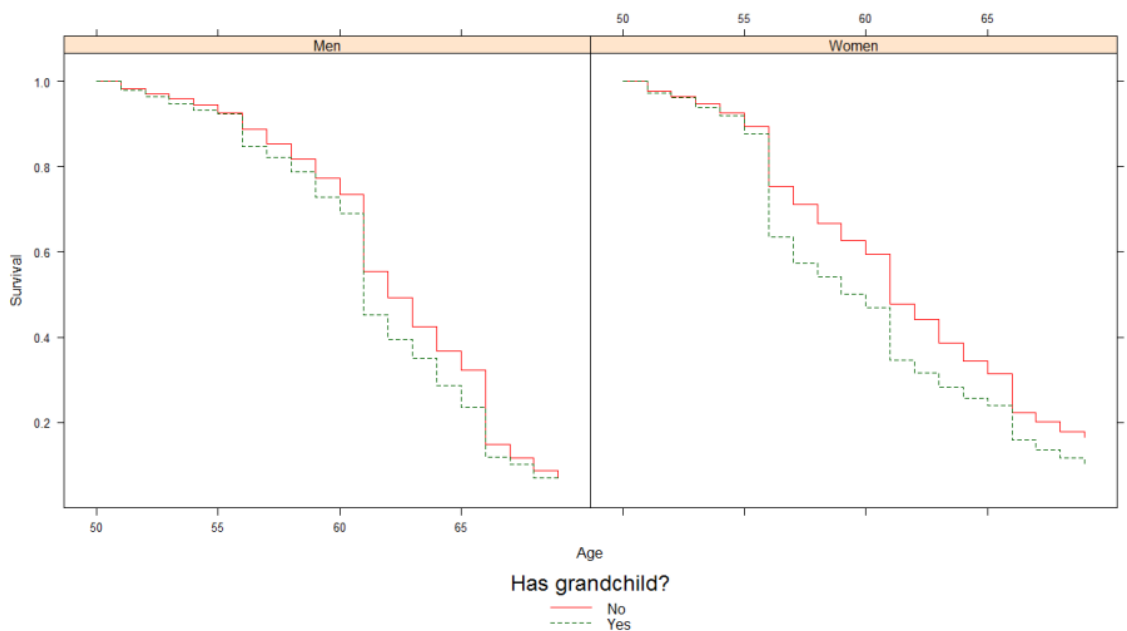

Figure 3. Life table survivor function for entry into retirement, all 22 countries pooled, by gender and grandparenthood status

Source: own calculations based on ESS3 


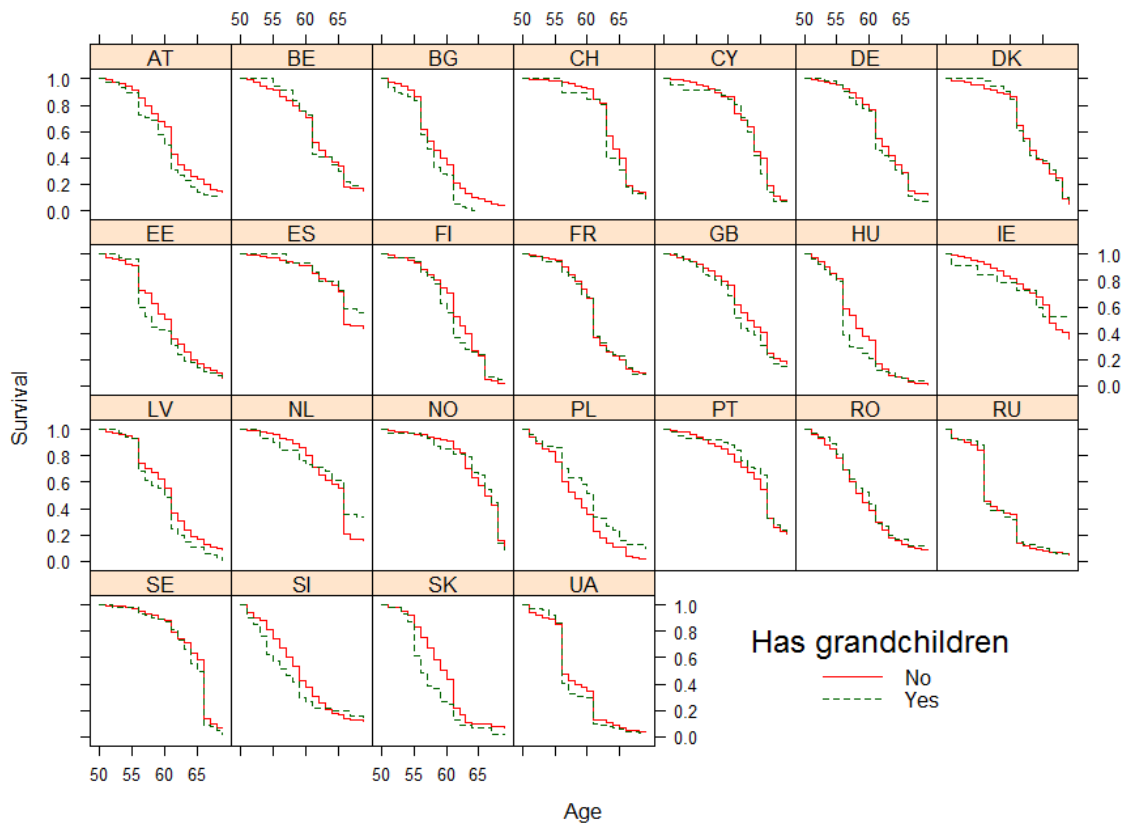

Figure $4 \quad$ Life table survivor curves for entry into retirement by country and grandparenthood status,

Source: Own calculations based on ESS3.

* Country codes: see Figure 1 . 


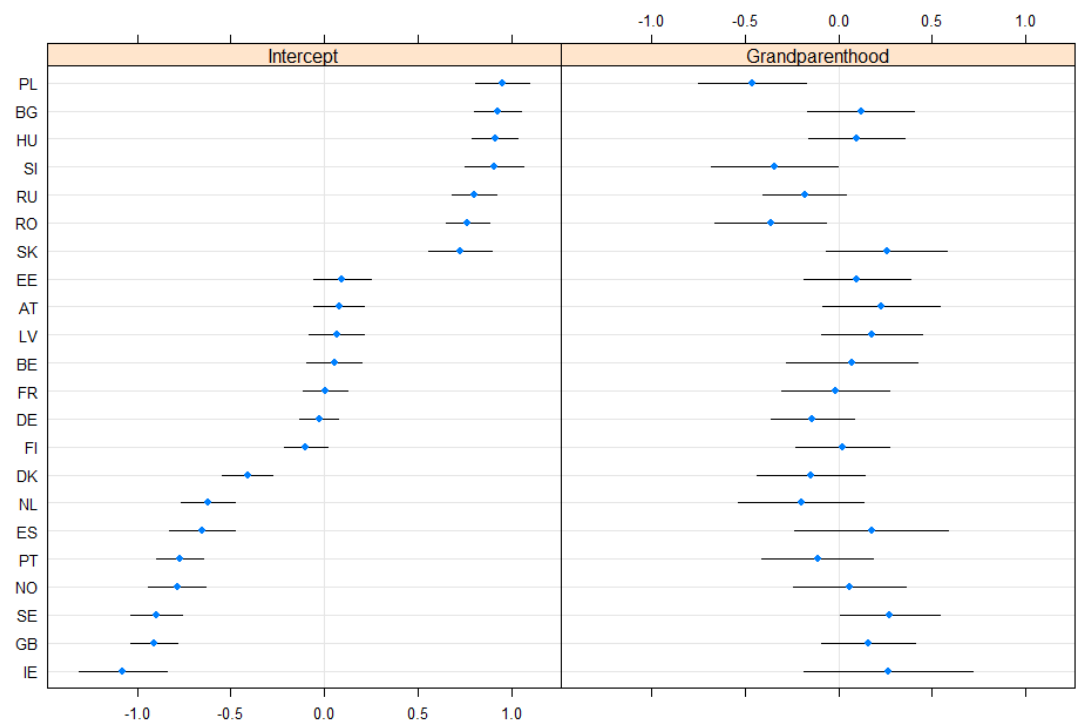

Figure $5 \quad$ Random country effects (BLUPs): intercept and slopes for grandparenthood (model (5))

Source: Own calculations based on ESS3

* Country codes: see Figure 1. 